\title{
DE NOMBRES, FÓRMULAS Y PRONUNCIACIONES
}

\section{NAMES, FORMULAS, AND PRONUNCIATIONS}

José Antonio Martínez Pons: Universidad Complutense de Madrid (España). jantonio.martinez@aol.com

\section{CURRÍCULUM VITAE}

Licenciado en Ciencias Físicas (Geofísica) por la Universidad Complutense de Madrid (España) y en ciencias químicas (Química física) por la UNED (España). Doctor por la Universidad de Alcalá de Henares (España) en el año 2000. Profesor de la Universidad de Alcalá de Henares en el área de Química Analítica e Ingeniería Química.

\section{RESUMEN}

Cada vez es más corriente encontrar incorrecciones y arcaísmos en la nomenclatura en prestigiosas revistas de diferente ámbitos. La cultura ha buscado siempre la máxima expansión y comunicación. Es por ello que en cada época existe una lengua que facilita el intercambio.

\section{PALABRAS CLAVE}

Lengua - Nombres - Incorrecciones 


\section{ABSTRACT}

It is increasingly common to find inaccuracies and archaisms in the nomenclature in prestigious journals in different fields. Culture has always sought the maximum expansion and communication. That is why each time there is a language that facilitates the exchange.

\section{KEY WORDS}

Language - Names - Misconduct

\section{TEXTO:}

La lectura de un trabajo en una "prestigiosa revista de física española" (y tal vez la única, por desgracia), con algunas incorrecciones y arcaísmos en nomenclatura química, me ha sugerido algunas reflexiones sobre la expresión científica. Helas aquí, desde mi modestia y sin ánimo de sentar cátedra alguna, ¿quién soy yo para ello?

La cultura ha buscado siempre la máxima expansión y comunicación, por ello es normal que, en cada época, exista una lengua franca que facilite el intercambio. Normalmente es la lengua del país más poderoso cultural, económica y militarmente, que todo suele ir junto. En nuestro área, el Mediterráneo, fue el griego, que permaneció durante la dominación romana, -los intelectuales romanos tenían a gala expresarse en griego, "Graecia capta, ferum victore coepit"-.

Al griego sucedió, en occidente, el latín que permaneció como lengua de cultura hasta bien entrado el siglo XVIII, Newton y Leibniz escribían en latín; y aún hoy los 
nombres científicos en biología se escriben en latín. La comunicación escrita en lengua latina era casi general y de comprensión universal y en las Universidades se explicaba en latín, pero la universalidad (siempre restringida al mundo europeo) de la comunicación oral no era tanta. Conviene recordar un antiguo cuento (cito de memoria) en que cuatro clérigos, de diferentes nacionalidades hablan entre sí en latín y todos piensan que sus interlocutores lo hacen en su respectiva lengua materna: "No le entiendo porque me habla en tudesco, pero si lo hiciera en latín habíale de confundir", dice el español.

Me cuentan quienes frecuentaron las universidades pontificas, cuando el latín era su lengua oficial, que comprender a los profesores angloparlantes era un tormento: Chanchummorrou por tantummodo, "nam" por "non" y "neim" por "nam" etc. Cosa que también constatamos los melómanos (un defecto como otro cualquiera) con las grandes obras sacras cantadas en "latín".

Al latín sucedió el francés y a éste le ha sucedido el inglés con un breve paréntesis, al menos en física, del alemán, con todo, el inglés no tiene ni la potencia ni la flexibilidad de las grandes lenguas clásicas, ni tampoco su precisión, ni siquiera su facilidad para crear neologismos con sentido. Quizás el aspecto más positivo del inglés, además de ser lengua viva, sea la relativa sencillez de su gramática, compensada con lo anárquico de su pronunciación.

Más universal que la lengua franca es la expresión simbólica, muy propia de las matemáticas, 127 es pronunciado de distinta forma por un francés, un ruso o un alemán, pero todos entienden su significado.

La química, como es bien sabido, ha desarrollado un lenguaje simbólico para expresar la composición de las especies químicas, así cualquier farmacéutico, sin entender el idioma de su cliente, sabe que éste quiere una aspirina si le escribe su 
fórmula. La lectura de estas fórmulas, la nomenclatura, es propia de cada idioma, con unas reglas más o menos flexibles, pero que conviene respetar. A pesar de todo, el peso anglosajón es fuerte y muchas veces se ve "calcio cloruro", por "cloruro de calcio", lamentables olvidos al decir tungsteno por wolframio (símbolo W) o barbaridades como "hidrógeno sulfurado", para hablar de H2S, silicona por silicio y no sólo en la prensa diaria, sino hasta en alguna revista de alta divulgación (también he leído reacciones "buey-rojo" por red-ox).

No creo, con todo, que deba hacerse un mundo por si un ion debe llamarse cloro o cloruro (más grave es confundir sus cargas), ni por olvidar que los nombres de los elementos y de las especies químicas son nombres comunes y, por tanto, a la normativa ortográfica de éstos deben sujetarse, por ejemplo, en el uso de mayúsculas.

En física, aparte del simbolismo de los cálculos, está el simbolismo de las unidades, que son esto, símbolos, no abreviaturas y como tales ni se pone el "." final, ni se pluralizan, ni se modifican. Del mismo modo que no es correcto simbolizar el potasio por Pot., no debería aceptarse ni seg. ni grs. ni mucho menos Mts, tan común en las señales de tráfico. Pienso que el simbolismo debería afectar también a las principales magnitudes físicas, no sólo a las unidades, de este modo las ecuaciones físicas (me resisto a la palabra fórmula) serían absolutamente simbólicas. De hecho, de forma oficiosa, casi se ha conseguido.

En cuanto a la nomenclatura, los físicos deberían imitar a los químicos. Con las magnitudes no existe problema: al trabajo le llamamos trabajo (o "labor" como D. Julio Palacios) y nadie ha pensado -de momento, el número de papanatas es infinito-, en "internacionalizarlo" a "working". Donde puede haber sus discusiones es con las unidades. Éstas o son nombres tradicionales, como metro o gramo, que están suficientemente enraizados en nuestra lengua, y tampoco a nadie se le ocurre 
"internacionalizarlos", o, como algunos elementos químicos, son homenaje a algún científico ilustre. La norma es que estos nombres no deben "castellanizarse", al contrario que los elementos, -por ejemplo, "einstenio", símbolo Es-, que si se castellanizan. Algunos nombres no exigen forzar demasiado nuestra fonética, por ejemplo "pascal"o "newton" que pronunciamos "niuton", pero con otros empezamos a poner caras raras y acabamos como los clérigos del cuento: "youl", "yul", "yaul", "joule", pronunciado a lo castizo con una "j" bien rotunda y con el diptongo "o-u". Otro ejemplo: "ampère". ¿Pronunciamos correctamente las "e" abierta o final, o la "r"? ¿No sería mejor quedarnos con el "julio" o el "amperio"? Más ejemplos: ¿Por qué, por huir del voltio nos vamos al "volt", con lo alérgico que es el castellano a dos consonantes juntas como fin de palabra? En última instancia, si lo que se pretende es homenajear al "signore Alessandro Volta", lo lógico sería hablar del "volta" no del "volt". Ítem más: ¿cómo pluralizamos, con una "s" final y que suene algo tan horrible como "volts"," niutons" o "amstrongs"?

Resumo, pienso que se debe ser muy riguroso con los símbolos, pero en la nomenclatura debe privar el respeto a nuestro idioma, al decir de C.J. Cela (senior), un don de los dioses, y eso incluye la fonética, aunque James Prescott Joule vea su nombre usurpado por Julio Palacios o Julio Gutiérrez, de todos modos, cualquier físico sabe a quién se debe el nombre de la unidad y no hay por qué torcer la boca para pronunciarlo, en general, mal, tan mal que dudo que el ilustre cervecero británico se reconociera en la mayoría de pronunciaciones "internacionales". (Desde luego Volta jamás se reconocería). Si no queda más remedio que el nombre internacional, entonces, siguiendo la escuela francesa, me apunto a la pronunciación castiza, y el plural en "es", como dice el refrán, "o todos moros, o todos cristianos".

Nota de V.A.: Es casi una exigencia no publicar en Vivat Academia artículos en otro idioma que el castellano, salvo ofertas de trabajo. Sin embargo, en esta ocasión hacemos una excepción con la versión de " El Señor de los anillos" que les ofrecemos, 
una crítica ácida, sobre el trabajo de aquellos que se inician en el mundillo universitario, escrita por alguien ajeno a nuestro sistema y enviada por uno de nuestros lectores. Observen que cualquier parecido con la realidad española no es mera coincidencia. 